\title{
MIGRAÇÕES INTERNAS E MALÁRIA URBANA - BAHIA, BRASIL
}

Sebastião Loureiro de Souza* Maria Inês Costa Dourado* Ceci Vilar Noronha *

SOUZA, S.L. de et al. Migrações internas e malária - Bahia, Brasil. Rev.Saúde públ., S.Paulo, 20: 347-51, 1986.

RESUMO: Estuda-se as características sócio-económicas dos indivíduos acometidos pela malária, em 1983, na área urbana de Camaçari - Bahia, Brasil, com destaque para os subgrupos migrantes e não migrantes. As condiçōes de vida precárias de ambos os subgrupos são apontadas como os determinantes do surto de malária desencadeado no local.

UNITERMOS: Malária, ocorrência. Fatores sócio-econômicos. Migração interna. Qualidade de vida.

\section{INTRODUÇÃO}

Admite-se que os processos sociais influenciam na transmissão e controle da malária $1,2,7,8$. Acrescente-se que os processos sociais, reconhecidamente, influenciam a intensidade e a distribuição da enfermidade, ou seja, a distribuição da malária na popula. ção não se dá ao acaso. É possível admitir certos padrōes de ocorrência da doença frente às características da população. Desta forma, as migrações se destacam como um processo social que influencia a densidade populacional em determinadas áreas favorecendo ou dificultando a transmissão da malária.

Cabe ainda precisar o enfoque com que se pretende explorar o fenômeno migratório. As migrações não constituem fenômenos isolados da estrutura social. Bem distante disso, elas guardam estreita dependência ao processo de expansão capitalista. Reitera-se, assim, as migrações como fenômenos sociais derivados da dinâmica da acumulação capitalista, nos moldes em que a mesma se realiza no país 6,9 .

Importa também estudar como as migrações ocorrem. As condições de vida dos grupos migrantes têm ainda maior relevância quando se reconhece que a população migrante, por vezes, se estabelece em locais de alta endemicidade da doença. Nestes locais existem, simultaneamente, maior dificuldade em realizar medidas de controle.

O trabalho de investigação realizado em Camaçari - Bahia propōe-se a caracterizar os movimentos populacionais na área e levantar as características so. ciais dos subgrupos migrantes e não migrantes, no conjunto da população malarífera.
O município de Camaçari faz parte da Regiâo Metropolitana de Salvador. Caracteriza-se como área de alto incremento demográfico com base nas migrações intemas, e como polo de desenvolvimento in. dustrial petroquímico.

A instalação das empresas industriais petroquímicas, na década de 70 , ocasionou a intensificação dos movimentos migratórios para a área.

\section{MATERIAL E MÉTODOS}

Em 1983, ocorreu em Camaçari um surto de malária, atingindo 239 indivíduos na sede municipal. A classificação destes casos registra três deles como importados e todos os demais como autóctones. O surto foi detectado em abril, atingindo seu ápice entre junho/julho, decrescendo em seguida.

A explicação da Superintendência de Campanhas de Saúde Pública (SUCAM) para a ocorrência do surto prende-se à chegada de indivíduos infectados de outras áreas para Camaçari, sem contudo especificar o Estado ou município de procedência desses casos. A perspectiva deste estudo, entretando, não é a de realizar investigação epidemiológica de casos, mas analisar, no grupo malarifero, a migração e os condicionantes sócio-econômicos enquanto questões inter-relacionadas.

Esta investigação é de natureza sócio-médica e tem um caráter complementar às ações de controle empreendidas pela SUCAM, na área. Assim, procedeu-se ao levantamento dos casos de malária diag. nosticados pela SUCAM e, com base nesses dados, foram realizadas en trevistas domiciliares.

\footnotetext{
* Do Departamento de Medicina Preventiva da Faculdade de Medicina da Universidade Federal da Bahia - Rua Padre Feijó, 29 - Canela - 40000 - Salvador, BA.
} 
Para a realização das entrevistas foi elaborado um questionário ${ }^{*}$ específico contendo variáveis de natureza biológica e sócio-econômica. As variáveis relacionadas com trabalho e renda foram obtidas para os chefes de familia. Tal estratégia se deve ao fato de que sendo o caso de malária, a criança ou a dona de casa, não se obteria informações que caracterizassem socialmente aquela família. As demais variáveis foram obtidas para todo o grupo.

Do total de casos de malária (239) foram entrevistados 204 indivíduos distribuídos por 179 familias. O trabalho de campo transcorreu nos meses de outubro e novembro de 1983 , sendo que a totalidade dos casos de malária não se encontrava mais residindo na área, naquele período.

\section{RESULTADOS}

O grupo de casos de malária é constituído por $84,4 \%$ (173) de indivíduos migrantes. Os não migrantes são minoritários, portanto $(15,4 \%)$.

Observa-se diferenças na distribuição dos casos de malária migrantes e não migrantes por faixas etárias, destacando-se que o subgrupo migrante é constituído, principalmente, por indivíduos em idade de trabalhar (acima de 14 anos). Entre os não migrantes ocorre o inverso, sendo estas diferenças estatisticamente significantes (Tabela 1).

\section{TABELA 1}

Casos de Malária Migrantes e Nāo Migrantes Segundo Idade. Camaçari, Bahią, 1983.

\begin{tabular}{ccccc}
\hline \multirow{2}{*}{ Idade } & \multicolumn{2}{c}{ Migrante } & \multicolumn{2}{c}{ Não Migrante } \\
& No & $\%$ & No & $\%$ \\
\hline $0-4$ & 14 & 8,1 & 11 & 35,5 \\
$5-14$ & 50 & 28,9 & 10 & 32,3 \\
$15-29$ & 60 & 34,7 & 05 & 16,1 \\
30 e mais & 49 & 28,9 & 05 & 16,1 \\
\hline T o t a 1 & 173 & 100,0 & 31 & 100,0 \\
\hline
\end{tabular}

$$
\mathrm{x}_{3}^{2}=20,51 ; \mathrm{p}<0,001
$$

Quanto ao sexo, foram encontradas proporções bem semelhantes para ambos os sexos entre os migrantes e não migrantes do grupo malarífero. Assim, encontrou-se entre os migrantes $56,1 \%$ de indivíduos do sexo masculino e $43,9 \%$ do feminino; no grupo não migrante havia $58,1 \%$ do sexo masculino e $41,9 \%$ do sexo faminino. Embora a proporção de indivíduos do sexo masculino seja superior ao feminino em ambos os subgrupos, não há diferenças estatisticamente significantes na composição por sexo dos subgrupos migrantes e não migrantes. (Tabela 2).

TABELA 2

Casos de Malária Migrantes e Não Migrantes Segundo Sexo. Camaçari, Bahia, 1983.

\begin{tabular}{lccccc}
\hline Sexo & \multicolumn{2}{c}{ Migrante } & \multicolumn{2}{c}{ Não Migrante } \\
& No & $\%$ & No & $\%$ \\
\hline Masculino & 97 & 56,1 & 18 & 58,1 \\
Feminino & 76 & 43,9 & 13 & 41,9 \\
\hline Tot a 1 & 173 & 100,0 & 31 & 100,0 \\
\hline
\end{tabular}

$\mathrm{X}^{2}=0,039 ; \mathrm{p}>0,05$

A característica espacial do fluxo migratório que se dirige para Camaçari é predominantemente do tipo urbano uma vez que aproximadamente $80 \%$ dos migrantes provêm de outras áreas urbanas (Tabela 3).

TABELA 3

Casos de Malária Migrantes Segundo Características da Área de Origem. Camaçari, Bahia, 1983.

\begin{tabular}{lccc}
\hline & Area & N & $\%$ \\
\hline Urbana & 133 & 78,2 \\
Rural & 37 & 21,8 \\
\hline Tot a l & $170^{*}$ & 100,0 \\
\hline
\end{tabular}

* Estão excluídos 3 migrantes sem esta informação.

Quanto ao local de nascimento, a grande maioria dos migrantes é originária do próprio Estado da Bahia $(75,6 \%$-. Tabela 4$)$

TABELA 4

Casos de Malária Migrantes Segundo o Local de Nascimento. Camaçari, Bahia, 1983.

\begin{tabular}{lrc}
\hline Local de Nascimento & No & $\%$ \\
\hline Estado da Bahia & 130 & 75,6 \\
Estados Nordestinos & 38 & 22,1 \\
Outros Estados do País & 04 & 2,3 \\
\hline T o t a l & $172 *$ & 100,0 \\
\hline
\end{tabular}

* Falta um migrante sem informação

\footnotetext{
* Cópia đo questionário poderá ser fornecida aos interessados, pelos autores do trabalho.
} 
Num segundo plano de importância aparecem os migrantes procedentes de outros Estados nordestinos $(22,1 \%$ - Tabela 4$)$. Tais indicações não parecem descabidas, visto que tradicionalmente o Nordeste perde população para o Centro-Sul do país ou para quaisquer outras áreas onde venham a se im. plantar grandes projetos econômicos.

Afora os Estados nordestinos, é mínima a contribuição $(2,3 \%)$ de outros Estados do pais na população estudada (Tabela 4).

Considerando o último local de moradia, que define o local de procedencia do grupo malarífero, independentemente do seu local de nascimento, vê-se a participação majoritária do Estado da Bahia (83\%) na composição dos casos de malária residentes em Camaçari (Tabela 5).

Os Estados do Nordeste representam o último local de moradia antes de Camaçari para 12,3\% do grupo. Os demais Estados do país (exceto os nordestinos) têm uma participação pouco expressiva (4.7\%) como último local de moradia antes de Camaçari (Tabela 5).

\section{TABELA 5}

Casos de Malária Segundo Último Local de Moradia Fora da Cidade de Camaçari, Bahia, 1983.

\begin{tabular}{lrc}
\hline \multicolumn{1}{c}{ Último Local de Moradia } & N & $\%$ \\
\hline Estado da Bahia & 142 & 83,0 \\
Estados Nordestinos & 21 & 12,3 \\
Outros Estados do País & 8 & 4,7 \\
\hline Total & $171^{*}$ & 100,0 \\
\hline
\end{tabular}

* Faltam dois migrantes sem informação.

No grupo estudado independentemente do fenomeno migratório, encontra-se uma associação entre área residencial e malária. Os casos diagnosticados desta enfermidade ocorreram entre migrantes e não migrantes residentes, principalmente em dois pontos da cidade: as invasões e os bairros tradicionais ou antigos. No entanto, os migrantes participam mais da moradia em áreas residenciais planejadas pelos poderes públicos $(18,5 \%$ - Tabela 6 ).

Não parece demasiado sublinhar o fato de que uma proporção superior a $50 \%$ dos casos de malária ocorreu nas áreas de invasão. Este fato encerra um sentido próprio na medida que se pode apreender. facilmente, que a doença ocorreu mais intensivamente entre os indivíduos menos favorecidos economicamente, tanto migrantes quanto não migrantes. Os bairros tradicionais da cidade, que constituiria a segunda área crítica para a transmissão da malária, estão longe de apresentar condições habitacionais com saneamento básico adequado.

\section{TABELA 6}

Casos de Malária Segundo Migração e Área Residencial em Camaçari, Bahia, 1983

\begin{tabular}{lccccc}
\hline \multirow{2}{*}{ Área Residencial } & \multicolumn{2}{c}{ Não migrante } & \multicolumn{2}{c}{ Migrante } \\
& Nọ & $\%$ & No & \multicolumn{1}{c}{$\%$} \\
\hline $\begin{array}{l}\text { Invasões } \\
\begin{array}{l}\text { Conjuntos } \\
\text { cionais }\end{array}\end{array}$ & 17 & 54,8 & 92 & 53,2 \\
$\begin{array}{l}\text { Bairros tradicionais } \\
\text { da cidade }\end{array}$ & 14 & 45,2 & 49 & 28,3 \\
\hline To t a 1 & 31 & 100,0 & 173 & 100,0 \\
\hline
\end{tabular}

$\mathrm{X}_{2}^{2}=8,21 ; \mathrm{p}<0,05.05$

Para a caracterização do grupo social malarífero foram levantados dados relativos ao trabalho e renda dos chefes de familia. Na distribuição dos chefes de familia do grupo malarífero por condições atuais de trabalho destacou-se os assalariados da indústria $(36,7 \%)$ e os trabalhadores por conta própria $(18,1 \%)$. Merece destaque também o alto percentual de desempregados $(22,6 \%)$ entre eles (Tabela 7$)$.

\section{TABELA 7}

Chefes de Família do Grupo Malarífero Segundo a Condição de Trabalho Atual. Camaçari, Bahia, 1983.

\begin{tabular}{lcr}
\hline \multicolumn{1}{c}{ Discriminação } & No & $\%$ \\
\hline Trabalho Por Conta Própria & 32 & 18,1 \\
Assalariado da Indústria & 65 & 36,7 \\
Assalariado do Comércio/Serviços & 08 & 4,5 \\
Funcionário Público & 20 & 11,3 \\
Outros & 12 & 6,8 \\
Desempregado & 40 & 22,6 \\
\hline Tot a l & $177^{*}$ & 100,0 \\
\hline
\end{tabular}

* Estão excluídos 2 chefes de família por falta de informação.

Os dados de renda dos chefes de familia revelaram que aproximadamente $80 \%$ deles percebiam até 2 salários mínimos, enquanto que apenas 3,0\% recebiam acima de 5. Para um grande número de

* Faltam dois migrantes sem informaçāo 
familias a renda do chefe era a única fonte de sobrevivencia do grupo (Tabela 8).

\section{TABELA 8}

Chefes de Familia do Grupo Malarífero Segundo a Renda Mensal. Camaçari, Bahia, 1983.

\begin{tabular}{lrr}
\multicolumn{1}{c}{$\begin{array}{c}\text { Rend a } \\
\text { (em salários mínimos) }\end{array}$} & No & $\%$ \\
\hline Menos de 1 SM & 13 & 12,2 \\
Mais de 1 a 2 SM & 71 & 67,0 \\
Mais de 2 a 3 SM & 15 & 14,2 \\
Mais de 3 a 5 SM & 4 & 3,8 \\
Mais de 5 SM & 3 & 2,8 \\
\hline Tot a 1 & $106^{*} 100,0$ \\
\hline
\end{tabular}

* Estão excluídos 40 chefes de família desempregados e mais 33 sem informação sobre a renda.

\section{DISCUSSÃO}

A primeira constatação é que há mais migrantes do que não migrantes entre os casos de malária, no entanto, a cidade de Camaçari é basicamente composta por elementos migrantes atraídos para o local durante a construção do polo petroquímico.

As características estudadas no subgrupo migrante permitem depreender que estas têm relação com o móvel de atraçáo para a área: as indústrias petroquímicas. Por isso, há principalmente migrantes em idade de trabalhar (acima de 14 anos) e de procedência urbana. Condizente com a característica econômica principal da área, o assalariamento na indústria destaca-se na condição atual de trabalho dos chefes de familia.

Camaçari recebe migrantes principalmente da Bahia e de outros estados nordestinos, dado pouco conclusivo para corroborar com a explicação do surto, sustentada pela SUCAM.

De acordo com Marques e Pinheiro5 a Amazónia legal brasileira é responsável por $94,9 \%$ dos casos de malaria, em 1980, restando portanto para as demais regiões $5,1 \%$. Seu estudo procura aferir os principais deslocamentos de casos de malária no país, seja a nivel interno da Região Amazônica seja da Amazônia para outras regiões, onde se planeja a erradicação da malária a curto prazo. No caso particular da Bahia os autores não identificaram um fluxo de casos de malária direto da Amazônia legal para este Estado. Entretanto, esse fluxo pode se dar de modo indireto. Vê-se que em Camaçari verifica-se a presença de migrantes nordestinos. Reportando mais uma vez ao estudo referido 5 , identifica-se um fluxo significativo de casos do sul do Pará para o Piauí, ca- racterizado pela migraçâo de retorno ao local de origem. Assim, é provável supor que em Camaçari há um potencial de importação de indivíduos infectados de malária procedentes do Piauí.

E sabido que os portadores de gametócitos em areas receptivas pode dar início à transmissão da malária, ocasionando a existência de focos de certa importância, a depender das caracteristicas da área e da população. $O$ foco originado em Camaçari, em 1983, foi considerado como o mais expressivo do ano4, não só pelo número de casos de malária mas também pela importância econômica da área aliada à condição de pobreza da sua população.

Destaca-se uma concentração expressiva dos casos de malária nas áreas de invasão demonstrando que houve uma distribuição desigual da enfermidade por áreas residenciais e, conseqüentemente, entre grupos populacionais distintos. Para as ações de controle da malária destaca-se a necessidade de uma ação especial nas áreas de invasões. Registrou-se uma associação estatisticamente significante entre área residencial e malária, válida para ambos os subgru. pos: migrantes e não migrantes.

Franco-Agudelo ${ }^{3}$ levanta uma crítica ao modo como a relação habitação e malária vem sendo abordada pela epidemiologia clássica, cuja abordagem é centrada nas condições físicas da habitação e suas implicações na transmissão e controle do impaludismo. Essa perspectiva clássica desconhece o fato de que a habitação traduz em si própria o poder aquisitivo de seus habitantes. Por sua vez, o poder aquisitivo dos indivíduos é determinado pelo modo como estes indivíduos estão inseridos na produção social de mercadorias.

$O$ estudo realizado em Camaçari permite acrescentar a essa perspectiva crítica da relação habitação e malária a importância da localização da habitação no espaço urbano que é, em si mesmo diferenciado em função dos diversos estratos sociais.

Conclui-se que os migrantes do grupo malarífe ro estudado não representam um grupo socialmente distinto dos não migrantes. Em outras palavras, as características comuns à maioria dos dois subgrupos expressam a condição de vida das populações economicamente menos favorecidas.

\section{AGRADECIMENTOS}

Ao Ministério da Saúde, através da Secretaria de Ciência e Tecnologia e, especialmente, à Diretoria da SUCAM, na Bahia, pela colaboração efetiva para a realização deste trabalho. 
SOUZA, S.L. de et al. [ Internal migration and urban malaria - Bahia, Brazil ]. Rev.Saúde públ., S.Paulo, $20: 347-51,1986$.

ABSTRACT: It is proposed to study the socio-economic characteristics of individuals who were infected with malaria in the urban area of Camaçari, Bahia, Brazil, in 1983. Special emphasis being given to the subgroups of migrants and nonmigrants. The precarious living conditions of both subgroups are identified as determinative of the malaria outbreak which occurred there.

UNITERMS: Malaria, occurrence. Socioeconomic factors. Transients and migrants. Quality of life.

\section{REFERËNCIAS BIBLIOGRÁFICAS}

1. COSTA, E.A. Movimentos migratórios e con1role de doenças: por uma epidemiologia social. Cad.Saúde públ.Ser.Ensaio, Rio de Janeiro, 3(1): 5-14, 1982.

2. FRANCO-AGUDELO, S. Los processos sócio-economicos en la transmission y el control de la malaria. Medellin, Universidad de Antioquia, 1983. [. Mimeografado].

3. FRANCO-AGUDELO, S. Elementos para un nuevo enfoque de la relacion malaria y vivenda. Medellin, Universidad de Antioquia, 1984. [ Mimeografado].

4. A MALARIA no Brasil. (Debate). Cad.Saúde públ, Rio de Janeiro, $1: 71 \cdot 111,1985$.

5. MARQUES, A.C. \& PINHEIRO, E.A. Fluxos de casos de malária no Brasil em 1980. Rev.bras.Malar., $34: 1-31,1982$.

6. MARTINE, G. Evolução e perspectiva da migração interna no Brasil. In: Seminário sobre Transmissão e Controle Tropicais no Processo de Migração Humana, Brasília, 1981. Doenças e migração humana; anais. Brasília, Centro de Documentação do Ministério da Saúde, 1982. p. 7-15.
7. ORGANIZACION PANAMERICANA DE LASALUD. Comite Asesor en Investigaciones Medicas y en Ciencias Sociales, Caracas, 1982 . Informe; 21 ? reunion. Washington, D.C., 1982. (OPS/CAIM/21/5).

8. ORGANIZACION PANAMERICANA DE LA SALUD. Comite Asesor sobre Investigaciones Medicas, México, D.F., 1983. Movimentos de población y la salud: necesidades mundiales en materia de investigacion: 22a reunion. Washington, D.C., 1983. (OPS/ CAIM/22/4.1).

9. SAWYER, D.R. Migraçōes humanas e doenças tropicais: fatores sociais. In : Seminário sobre Transmissão e Controle de Doenças Tropicais no Processo de Migração Humana, Brasília, 1981. Doenças e migração humana; anais. Brasília, Centro de Documentação do Ministério da Saúde, 1982. p. 121-33.

Recebido para publicaçāo em 08/01/1986

Reapresentado em 21/07/1986

Aprovado para publicação em 29/07/1986 